\title{
Sapstain of Japanese Black Pine Caused by Ophiostoma piceae in Korea
}

\author{
Jae Jin Kim¹, Min Woo Hyun², Dong Yeon Suh², Yeo Hong Yun², Seong Hwan Kim²* and Sang Chul Shin ${ }^{3}$ \\ ${ }^{1}$ Division of Environmental Science and Ecological Engineering, Korea University, Seoul 136-701, Korea \\ ${ }^{2}$ Department of Microbiology and Institute of Basic Sciences, Dankook University, Cheonan 330-714, Korea \\ ${ }^{3}$ Division of Forest Insect Pests and Diseases, Korea Forest Research Institute, Seoul 130-012, Korea \\ (Received on August 11, 2010; Accepted on September 9, 2010)
}

Sapstain fungi that cause blue or black discolorations of sapwood in diverse trees are one of the important fungal groups in forest health as tree pathogens, and in forest products industry as wood-stainers (Seifert, 1993). Sapstain, caused by fungi, is the cosmetic damage of wood that reduces wood quality and the values of commercial wood products. In July 2006, bluish or brown colored signs of sapstain were found on cut sapwood of Japanese black pine (Pinus thunbergii) in Taean, Korea (Fig. 1A). The signs of sapstain were also found on cut sapwood of Japanese black pine infected with pinewood nematode in Jinju in June 2007. Voucher specimens were deposited at Dankook University Culture Collection, Cheonan, Korea(DKM 0510, 0410, 0412, 0413, 0601).

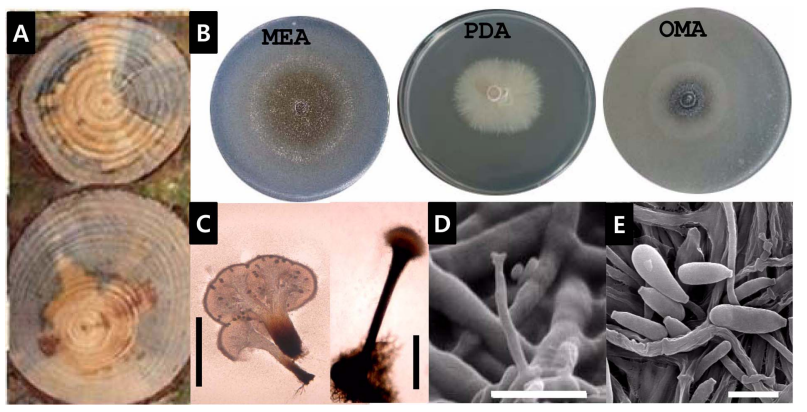

Fig. 1. A: Signs of stain on two pine wood cuts. B: Colony characteristics of Ophiostoma piceae grown on $2 \%$ MEA, PDA, and OMA at $25^{\circ} \mathrm{C}$ for 5 days. C: Light microscopic micrograph of pigmented synnema with Pesotum anamorph. D: SEM micrographs mononematous synnema with Sporothrix synanamorph. E: SEM micrograph of conidia. Scale bar $=250$ $\mu \mathrm{m}$ for $\mathrm{C}$ and $10 \mu \mathrm{m}$ for $\mathrm{D} \& \mathrm{E}$.

The fungal colony was brown and dark on MEA, light brown on PDA and black on oat meal agar (Fig. 1B). Optimal growth temperature and $\mathrm{pH}$ for the fungus was 22 and $\mathrm{pH}$. The fungus showed tolerance to cycloheximide $(250 \mu \mathrm{g} / \mathrm{ml})$. The optimal $\mathrm{pH}$ for growth was on PDA and MEA. Observation of morphological features on a phase-contrast light microscope (Karl Zeiss Axioskop 40) and a scanning electron microscope (Hitachi S-4200) revealed that the fungus has Sporothrix and Pesotum anamorph of O. piceaecomplex. Conidial mass on apex of synnema was milky color. Synnema were dark brown and 500-1300 (-1600) $\mu \mathrm{m}$. Synemmatous conidia were hyaline and 5-15×1-3.5 $\mu \mathrm{m}$ (Fig. 1C-E). Perithecia and ascospores were not found in our cultures.

To confirm the identity of this fungus, partial $\beta$-tubulin gene was amplified with primers T10 and BT12 (Kim et al., 2003) and directly sequenced. The determined nucleotide sequence was deposited in GenBank (EU012505). The determined sequence shared 100\% sequence identity with those of $O$. piceae. Based on $\beta$-tubulin gene sequence, a cladogram was constructed using PAUP by the neighbor-joining method with the heuristic search option (Swofford, 2002). The fungus grouped with $O$. piceae (Fig. 2). This molecular data confirmed the fungus is $O$. piceae. An inoculation test on wood chips of Japanese pine displayed that the fungus colonized and developed dark and/or brown stain in the chips (Fig. 3B). On the

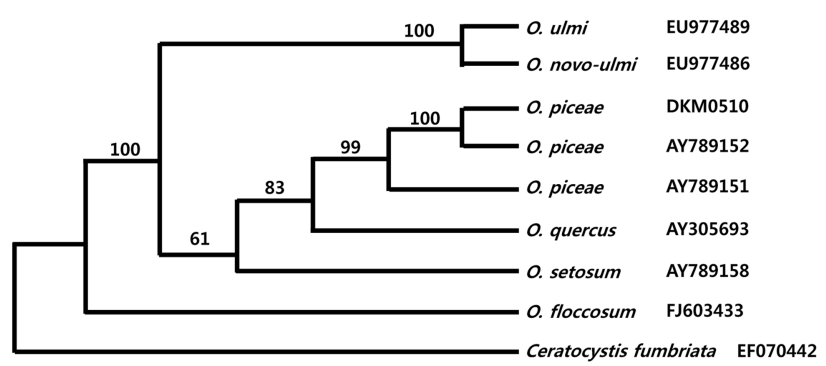

Fig. 2. Phylogenetic position of the isolated fungal species in Ophiostoma piceae complex group. Cladogram was constructed based on $\beta$-tubulin gene sequences by the neighbor-joining method. Numbers above the node represent the bootstrap values.

inoculated chip, the fungus formed its typical brown pigmented synnema having a droplet of conidial mass (Fig. 3C).

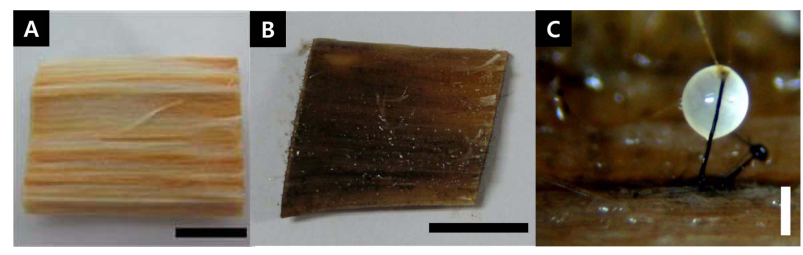

Fig. 3. Inoculation test of Ophiostoma piceae on wood chips. A: Control of uninoculated chip. B: Inoculated chip. C: Pigmented synnemata formed on wood chip surface of B. Scale bar $=1 \mathrm{~cm}$ for A \& B and $250 \mu \mathrm{m}$ for C.

So far, more than 150 species of Ophiostoma have been described, but their occurrence has rarely been studied in Korea. This is the first report of $O$. piceae in Korea. Since we isolated $O$. piceae from a pine diseased by pinewood nematode that recently has devastated pine trees in Korea, further study on Ophiostoma fungi should be done to explore their impact on forest health and wood discoloring damage.

\section{Acknowledgements}

This research was supported by a Korea University Grant and by Korea Forest Research Institute.

\section{References}

Kim, J. J., Lee, S., Kim, S. H. and Breuil, C. 2003. Distinguishing Ophiostoma ips and Ophiostoma montium, two bark beetle-associated sapstain fungi. FEMS Microbiol. Lett. 222:187-192.

Seifert, K. A. 1993. Sapstain of commercial lumber by species of Ophiostoma and Ceratocystis. In: Ceratocystis and Ophiostoma. Taxonomy, Ecology and Pathogenicity. ed. by M. J. Wingfield, K. A. Seifert and J. F. Webber. pp. 141-151, APS Press, St. Paul, MN. USA.

Swofford, D. L. 2002. PAUP*: Phylogenetic analysis using parsimony (and other methods) 4.0 Beta for Macintosh. Sinauer Associates Inc., Sunderland, Mass.

*Corresponding author (piceae@dankook.ac.kr) 